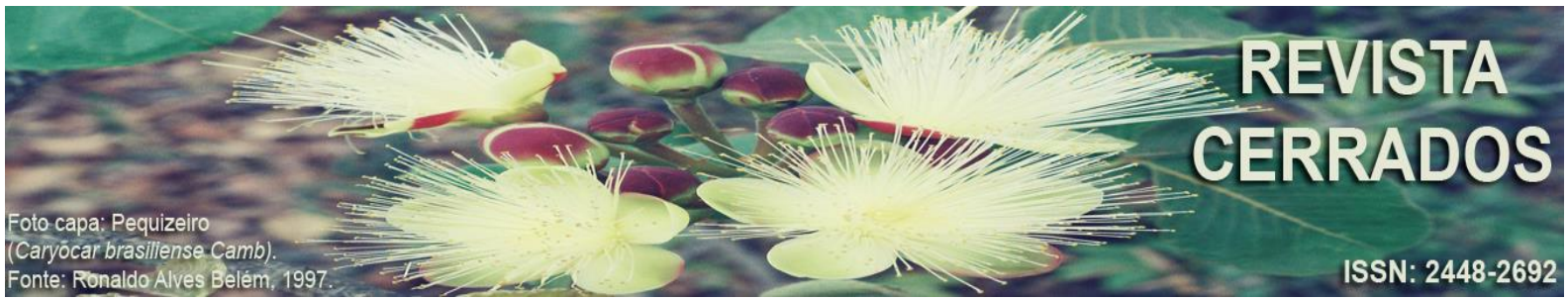

\title{
A PRODUÇÃO DO ESPAÇO URBANO A PARTIR DO PROGRAMA MINHA CASA MINHA VIDA: inserção urbana e/ou desigualdades socioespaciais em Marabá - PA
}

\author{
THE PRODUCTION OF URBAN SPACE FROM THE PROGRAM \\ MINHA CASA MINHA VIDA: urban insertion and / or sócio-spatial \\ inequalities in Marabá - PA
}

\section{LA PRODUCCIÓN DEL ESPACIO URBANO DESDE PROGRAMA MINHA CASA MINHA VIDA: integración urbana y / o desigualdades socio- espaciales en Marabá - PA}

\author{
Marcus Vinicius Mariano de Souza \\ Universidade Federal do Sul e Sudeste do Pará - UNIFESSPA \\ E-mail: <marcussouza@unifesspa.edu.br>
}

\begin{abstract}
Resumo
O presente trabalho teve como objetivo analisar a produção do espaço urbano na cidade de Marabá (PA) a partir da lógica estatal, por meio da construção de conjuntos habitacionais do Programa Minha Casa Minha Vida, de forma que se procurou verificar se esta produção tem possibilitado a inserção urbana das novas áreas ou levado ao estabelecimento de desigualdades socioespaciais. Tendo como referência espacial o Residencial Vale do Tocantins e a partir da aplicação de formulários neste local concluiu-se que a produção do espaço pela lógica estatal tem ampliado as desigualdades socioespaciais, na medida em que a decisão de se estabelecer neste local não pertence à sua população e não lhes foram dadas condições mínimas para reprodução social na cidade, manifestada na ausência dos equipamentos públicos de consumo coletivo. A ausência de escolas e postos de saúde e as dificuldades de locomoção dos moradores através do transporte público coletivo configuram a dificuldade de inserção urbana a que esta população está submetida.
\end{abstract}

Palavras-chave: Produção do espaço urbano; desigualdades socioespaciais; inserção urbana; Marabá. 


\begin{abstract}
This study aimed to analyze the production of urban space in the city of Maraba (PA) from the state logic through the building housing the Minha Casa Minha Vida, so we tried to verify that this production has enabled the urban integration of the new areas and led to the establishment of socio-spatial inequalities. With the spatial reference the Residential Vale do Tocantins and from the application forms at this location it was found that the production of space by the state logic has expanded the socio-spatial inequalities, in that the decision to establish this site does not belong to your population and not have been given minimum conditions for social reproduction in the city, manifested in the absence of public facilities for collective consumption. The absence of schools and health centers and the difficulties of locomotion of the residents through collective public transportation constitute the difficulty of urban insertion to which this population is submitted.
\end{abstract}

Key-words: Production of urban space; socio-spatial inequalities; urban integration.

\title{
Resumen
}

Este estudio tuvo como objetivo analizar la producción del espacio urbano en la ciudad de Marabá (PA) a partir de la lógica de estado a través del edificio que alberga el Minha Casa Minha Vida, así que tratamos de verificar que esta producción tiene permitido a la integración urbana de las nuevas áreas y llevado a la creación de las desigualdades socio-espaciales. Con la referencia espacial del Residencial Vale do Tocantins y de los formularios de solicitud en este lugar se encontró que la producción del espacio por la lógica de estado ha ampliado las desigualdades socio-espaciales, en el que la decisión de establecer este sitio no pertenece a su población y no se han dado las condiciones mínimas para la reproducción social en la ciudad, que se manifiesta en la ausencia de espacios públicos para el consumo colectivo. La falta de escuelas y centros de salud y las dificultades de circulación de los residentes a través de transporte público configura la dificultad de inserción urbana que esta población se somete.

Palabras-clave: Producción del espacio; desigualdades socio-espaciales; integración urbana.

\section{INTRODUÇÃO}

A produção do espaço urbano, analisada pelo viés da produção material da cidade, tem se manifestado na cidade contemporânea por meio de diferentes lógicas, segundo os preceitos de Abramo (2010), como a lógica de mercado, a da necessidade e a estatal. Esta última tem se apresentado na paisagem das cidades, enquanto forma urbana, através da construção de conjuntos habitacionais, sobretudo a partir da criação do Programa Minha Casa Minha Vida (PMCMV), a partir de 2009. 
Autoras como Shimbo (2010) e Fix (2011) concordam que a política habitacional 'atual' (final da primeira década do século XXI) se apresenta em duas faces distintas: em uma delas, o poder público financia e produz diretamente a habitação, como no caso dos programas habitacionais tradicionais; do outro lado, o mesmo poder público procede a um conjunto de medidas, como a flexibilização e ampliação de crédito, para favorecer a produção pelo setor privado estimulando o mercado imobiliário.

O PMCMV acabou por se tornar o grande impulsionador da produção imobiliária (MELAZZO, 2013), pois, lançado como uma medida anticrise (em razão da crise econômica internacional de 2008), ampliou o volume de crédito e subsídios para aquisição e produção de moradias, sobretudo no chamado 'segmento econômico', que compreende moradias de valor entre 100 e 200 mil reais (CARDOSO; ARAGÃO, 2011).

O exemplo de Marabá demonstra a atração de investimentos do PMCMV para as cidades médias e de porte médio do Sudeste Paraense, através da estratégia de ampliação geográfica da atuação de empresas tanto do mercado imobiliário quanto da construção civil, impulsionadas pelo referido programa habitacional, mas também atraídas para cidades do Sudeste Paraense por conta das dinâmicas econômicas locais, como no caso de Marabá, cidade já estabelecida enquanto polo regional e para a qual se projetava a instalação de um empreendimento siderúrgico, a partir de 2008, que geraria mais de 16 mil empregos durante sua fase de construção, o que provocou uma nova dinâmica para a cidade, tanto no que se refere aos afluxos populacionais a ela destinados, como também nos investimentos sobre o mercado imobiliário, além de alterar as dinâmicas de produção do espaço urbano até então existentes.

De tal maneira, a chegada de investimentos habitacionais nestas cidades, por meio da criação de conjuntos habitacionais, poderia dar uma importante contribuição para a diminuição do déficit habitacional urbano. Entretanto, autores como Maricato (2009) já apresentavam preocupações com relação aos rumos do programa, principalmente com os problemas que poderiam ser gerados em decorrência, principalmente, da localização inadequada destes no espaço urbano.

Como afirma autora supramencionada, a habitação urbana é uma mercadoria especial, que exige terra urbanizada para sua realização. Entretanto, isto parece que não está ocorrendo com o PMCMV, de forma que o que se percebe a partir da instalação destes 
conjuntos é a exacerbação de outros problemas, que contribuem para a ampliação das desigualdades socioespaciais. Entre tais problemas está a falta de equipamentos públicos de saúde e educação nestes conjuntos, reforçando o problema da inserção urbana, entendido aqui a partir de Ferreira (2012), cujos parâmetros para análise são a presença e otimização da infraestrutura e serviços urbanos; a localização e acessibilidade e a fluidez urbana.

Nesse sentido, o objetivo do presente trabalho é analisar a produção do espaço urbano de Marabá, a partir da instalação de conjuntos habitacionais do Programa Minha Casa Minha Vida, de modo a verificar se este viés de produção espacial está garantindo a inserção urbana das novas áreas e sua população ou, de modo contrário, tem provocado a ampliação de desigualdades socioespaciais na referida cidade. Para tal, a análise teve como recorte espacial o Residencial Vale do Tocantins, primeiro conjunto do PMCMV entregue à população marabaense, no ano de 2012.

Para o desenvolvimento do trabalho adotou-se como embasamento analítico a perspectiva de Abramo (2010), que considera o estabelecimento de lógicas diferenciadas de produção do espaço urbano contemporâneo, com destaque para a lógica estatal; utilização do conceito de inserção urbana elaborado por Ferreira (2012), enquanto escala de análise que relaciona o empreendimento à cidade e ao bairro em que está inserido, tendo vista aspectos como acessibilidade, presença de serviços urbanos e integração à malha urbana.

Além disso, também enquanto embasamento teórico adotou-se o conceito de desigualdades socioespaciais a partir da perspectiva de Rodrigues (2007), que considera este processo expressão espacial da existência de classes sociais e de diferentes formas de apropriação da riqueza produzida, que irá se expressar na impossibilidade da maioria dos cidadãos em apropriar-se de condições adequadas de sobrevivência.

Como procedimentos metodológicos, além da pesquisa bibliográfica e do levantamento de dados primários e secundários, procedeu-se à aplicação de formulários no Residencial do Tocantins, com objetivo traçar um perfil das populações destes locais e compreender como se dá o acesso à cidade e aos equipamentos coletivos públicos, a fim de verificar se a produção do espaço urbano recente tem levado à ampliação das desigualdades socioespaciais ou se a inserção urbana está sendo plenamente realizada.

De tal forma, utilizando-se da técnica de amostragem aleatória simples, com nível de confiança de 95\%, foram aplicados 285 formulários, para um universo de 1.090 
residências. A partir da aplicação dos formulários e sua posterior análise foi possível perceber as estratégias da população residente neste local, no que diz respeito ao acesso desta à cidade e aos equipamentos e serviços básicos de consumo coletivo, demonstrando que a produção do espaço urbano a partir da lógica estatal tem colaborado para dificultar inserção urbana destas áreas e seus moradores e, por conseguinte, permitindo a ampliação das desigualdades socioespaciais, como será descrito no decorrer deste trabalho.

\section{Breves considerações sobre a produção do espaço urbano}

A análise que se constrói a seguir a respeito do conceito de produção parte da tentativa de se enxergar a realidade pelas lentes da Geografia, ao se pensar o referido conceito pelo viés espacial. Para tanto, é possível tomar como referência teórica o debate com diversos autores que dialogam com a obra de Henri Lefebvre (1991), como Carlos (2008; 2011), Godoy (2008), Soja (1993) e Sposito (2004).

No pensamento de Lefebvre, o conceito de produção aparece com um duplo sentido: primeiramente com um caráter de historicidade, sendo este um sentido mais amplo, em que se produz de tudo o que faz da sociedade uma civilização, como as obras, ideias, espiritualidade, ideologias. Já no outro sentido, sentido mais restrito, este processo aparece como sendo produção material, de bens, alimentos, habitação, das coisas (GODOY, 2008; SPOSITO, 2004).

Mas o que se pretende neste momento é pensar a produção do espaço e, de forma mais objetiva, do espaço urbano. A cidade é a própria manifestação da produção, nos dois sentidos de Lefebvre, pois ela é a expressão tanto do sentido amplo, ligada ao processo de urbanização e também é o ambiente que se materializa para a produção, no sentido restrito, enquanto locus para a produção de bens e serviços.

Ao falar sobre a produção do espaço no pensamento de Lefebvre, Godoy (2008, p.126) afirma que:

A concepção de Lefebvre sobre a 'produção do espaço' não implica numa leitura ortodoxa da produção-circulação-consumo, ou mesmo da espacialização do valor. $\mathrm{O}$ conceito possui um sentido histórico e sócio-cultural por conter uma dimensão temporal, subsumindo a historicidade do conceito de trabalho e uma dimensão espacial definida no momento da objetivação do trabalho concreto e do trabalho abstrato. 
Estas palavras vêm de encontro ao que se afirmou anteriormente, a respeito da produção do espaço urbano, em que há uma produção do espaço ligada, primeiramente, a um processo mais amplo, que é a própria urbanização e também uma produção material do espaço urbano, com aquilo que Godoy (2008) chamou de objetivação do trabalho. Porém, anterior a isto, é preciso deixar claro que Lefebvre (1991), em sua obra 'A produção do espaço', tinha como proposição desenvolver a ideia de que o espaço (social) é um produto (social); assim, cada sociedade (ou modo de produção) produz o seu espaço. Assim, esta relação se apresenta de forma dialética, com as contradições e aproximações entre as relações sociais e produtivas, uma dialética socioespacial, que a partir do pensamento de Lefebvre possui as seguintes premissas:

\begin{abstract}
A estrutura do espaço organizado não é uma estrutura separada, com suas leis autônomas de construção e transformação, nem tampouco é simplesmente uma expressão da estrutura de classes que emerge de relações sociais (e, por isso, aespaciais?) de produção. Ela representa, ao contrário, um componente dialeticamente definido das relações de produção gerais, relações estas que são simultaneamente sociais e espaciais (SOJA, 1993, p.99).
\end{abstract}

A respeito da reprodução do espaço urbano, Carlos (2008) afirma que este processo recria as condições gerais a partir das quais se realiza o processo de reprodução do capital, aproximando os meios de produção material, como a indústria, e também as pessoas (consumidores). A cidade é colocada como sendo o locus da concentração de meios de produção e concentração de pessoas, é o lugar da divisão econômica, social e espacial do trabalho (CARLOS, 2008). A cidade é produto e condição da produção / reprodução espacial.

A produção, portanto, que se dá em um sentido amplo e também em um restrito, será afetada pela conjuntura momentânea das forças produtivas, de como elas se apresentam em determinados momentos históricos. A produção do espaço urbano irá refletir estas condições, os arranjos políticos, econômicos, sociais e culturais de uma dada realidade espacial.

Em outra oportunidade, Carlos (2011) afirma que no presente momento histórico há a predominância de fenômenos globais, que sinalizam para constituição de uma totalidade nova, caracterizada pela sociedade urbana e pela criação de um espaço mundial. Sob a égide da globalização, estabelecem-se novos padrões, como a afirmação de uma sociedade de consumo, que influencia na produção do espaço, determinada pela busca de valorização do 
capital (pressuposto necessário para que a produção ocorra). Para a autora, no processo de 'produção da vida', a reprodução desta depare-se com as necessidades de reprodução do capital. Assim,

\begin{abstract}
Como consequência, a produção do espaço, fundada (sob o capitalismo) na contradição valor de uso/valor de troca, que domina e assegura o processo de acumulação no espaço por meio de sua reprodução. Como valor de troca, o espaço é a expressão mais contundente da desigualdade que se desdobra na contradição característica da reprodução do espaço capitalista - produção social/apropriação privada - que se manifesta no plano da forma espacial da segregação como evidência da justaposição entre morfologia social e morfologia espacial (CARLOS, 2011, p.50).
\end{abstract}

Vale destacar aqui que se concorda com Sposito (2004), quando esta afirma que a produção material da cidade é uma das perspectivas a partir da qual a cidade e a urbanização podem ser lidas. Este destaque é necessário, pois o que se desenvolve no decorrer deste trabalho parte por tal viés, da produção do espaço urbano em Marabá pensada por meio da expansão territorial da cidade, engendrada pelas práticas socioespaciais de diferentes agentes sociais, mas sem deixar de levar em consideração que "essa produção é também definida no plano abstrato, tanto individual como coletivamente" (SPOSITO, 2004, p.52).

Além disso, também aqui se concorda com Soja (1993), que ao dialogar com Lefebvre, conclui que o espaço socialmente produzido reproduz as relações de produção dominantes, o que conduz a uma espacialidade criada por um capitalismo que avança, sendo esta "fragmentada em pedaços, homogeneizada em mercadorias distintas, organizada em posições de controle e ampliada pela escala global" (SOJA, 1993, p.115).

Pensando então, no modo de produção capitalista e na produção do espaço que se dá a partir da correlação de forças que se estabelece entre os processos de reprodução social, não se pode deixar de levar em consideração a expansão territorial da cidade baseada na apropriação privada do espaço, mas também a partir das estratégias do Estado, em particular no caso brasileiro do PMCMV, com a construção dos conjuntos habitacionais na cidade, objeto de análise neste trabalho. 


\section{O PMCMV e a produção do espaço urbano}

Segundo Fix (2011), durante a crise internacional de 2008 percebeu-se que as ações na bolsa de valores ligadas aos empreendimentos imobiliários apresentavam um forte viés especulativo, fazendo com que muitas empresas não pudessem cumprir as metas prometidas. Pelo fato da construção civil ser um setor que gera expressiva quantidade de empregos, isso é usado pelo governo para apresentar um pacote de medidas para superar a crise, que tem como carro-chefe o Programa Minha Casa Minha Vida (PMCMV), lançado em abril de 2009 (FIX, 2011).

Fix (2011) demonstra que a articulação entre o empreendedor imobiliário e os segmentos políticos locais é capaz de levar à alteração da legislação local (como as leis que definem o perímetro urbano, por exemplo), a fim de se disponibilizar terra até então rural em um mercado imobiliário urbano, favorecendo não apenas as empresas incorporadoras e os associados a elas, mas também os proprietários fundiários locais (por vezes, inseridos na classe política) cujas terras, nem sempre, são aquelas mais adequadas à promoção imobiliária, mostrando outra faceta destas estratégias, que é a incorporação de áreas precárias em infraestruturas e condições de acesso, como já afirmava também Botelho (2007).

Este processo de promover a incorporação urbana de áreas já precárias em infraestruturas e acessos acarreta em outro problema, que é onerar os cofres públicos pela necessidade de se levar até estas novas áreas os equipamentos básicos à reprodução social, como as redes de infraestruturas, transporte público, equipamentos de saúde, educação e lazer, entre outros. Nesse sentido, o PMCMV 'colaborou' para a apropriação de renda pelos proprietários de terra e no aumento das desigualdades para os moradores do programa.

\footnotetext{
O espraiamento resultante desse modelo tem alto custo para o poder público, uma vez que a rede de infraestrutura (sistema viário, água, saneamento, energia, etc.), transportes e serviços (escola, cultura, lazer, etc.) terá que ser estendida. O pacote foi inicialmente lançado sem estímulo à ocupação de imóveis construídos vagos, apesar dos inúmeros edifícios vazios existentes nos centros urbanos e das políticas urbanas já elaboradas para favorecer seu uso. Prevalece, assim, a lógica de produção que interessa ao setor da construção (FIX, 2011, p.143).
}

Percebe-se que o PMCMV contribuiu para a ampliação das desigualdades socioespaciais em algumas cidades, como se pretende demonstrar a seguir, pois ele não atacou diretamente o problema do déficit habitacional, já que possibilitou a incorporação de 
terras e consequente expansão territorial da cidade através da disponibilização de créditos para a criação de loteamentos, por exemplo, e não pela criação da moradia efetiva.

\section{As novas dinâmicas contemporâneas das lógicas de produção do espaço urbano em Marabá}

A ocorrência de novas dinâmicas referentes às lógicas de produção do espaço urbano em Marabá tem como fundamento principal a possibilidade da chegada de um grande empreendimento siderúrgico a esta cidade, chamado de ALPA (Aços Laminados do Pará), atraindo fluxos de pessoas, mercadorias e investimentos. A partir de então começa a se configurar um novo cenário no que diz respeito à expansão do tecido urbano de Marabá, com o aparecimento, por um lado, de empreendimentos imobiliários dos mais diversos tipos (loteamentos, loteamentos fechados, condomínios fechados verticais e horizontais) e, de outro, o surgimento e ampliação das ocupações urbanas, além dos conjuntos habitacionais do PMCMV. De tal forma, entre os anos de 2009 e 2013 houve um crescimento de 35\% da área urbana de Marabá (SOUZA, 2015), conforme apresenta o Mapa 1 a seguir.

\section{Mapa 1 - Marabá (PA): Expansão urbana 2009 - 2013}

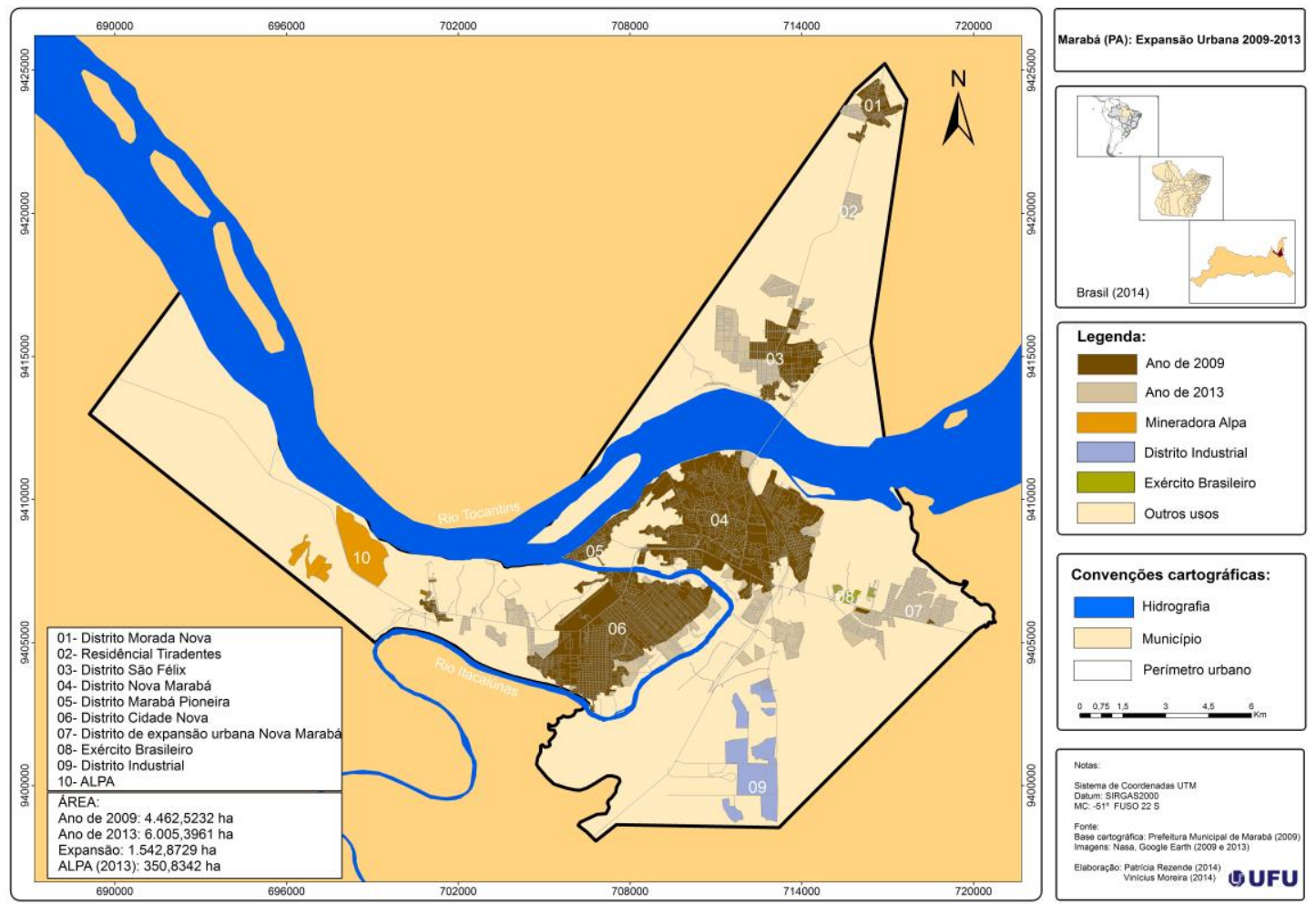

Fonte: SOUZA (2015). 
Anteriormente à notícia da chega da ALPA os movimentos do mercado imobiliário em Marabá, através do lançamento de empreendimentos, ainda eram incipientes. No período anterior a 2008 são poucos os empreendimentos característicos da difusão de um "novo habitat urbano" (SPOSITO, 2006) em Marabá, sob a forma de loteamentos ou condomínios. Este fatos demonstram a importância dada à expansão urbana ocorrida a partir de 2009, representada no Mapa 1 anterior.

Mas após a veiculada chegada da ALPA em Marabá é que realmente foi possível observar uma expansão urbana baseada na incorporação de terras rurais ao tecido urbano e sua transformação, principalmente, em loteamentos, sobretudo nos anos de 2009 e 2010. Entre os anos de 2009 e 2014 foram lançados e aprovados pelo Conselho do Plano Diretor para se instalarem em Marabá trinta e dois (32) empreendimentos imobiliários, que em sua maioria, disponibilizava no mercado lotes e não a moradia propriamente dita. No referido período, 30.282 lotes foram disponibilizados no mercado imobiliário de Marabá (SOUZA, 2015).

Entretanto, a possibilidade de chegada da ALPA foi o fator que possibilitou a valorização do capital imobiliário e sua reprodução espacial na forma de loteamentos e condomínios e, ao mesmo tempo, colaborou para a ampliação de outras estratégias de reprodução do espaço urbano, ao sobrepor o valor de troca ao valor de uso, dificultando o acesso universal à terra urbana (e à propriedade), culminando com o crescimento e criação de ocupações urbanas, sobretudo nas áreas menos atrativas ao mercado imobiliário.

Em 2010, segundo a Fundação João Pinheiro (2013), o déficit habitacional urbano de Marabá era de 10.969 domicílios, equivalentes a 22,5\% do total de domicílios particulares permanentes urbanos. Porém, a oferta de lotes e de imóveis particulares surgidos após 2008 é três vezes superior ao déficit habitacional urbano, o que demonstra que estas propriedades não são lançadas com pretensões de combater o déficit habitacional (o que deveria, já que possuem subsídios e créditos de instituições financeiras públicas para sua efetivação), mas sim com vistas a reprodução ampliada do capital, através, sobretudo, da especulação imobiliária.

Porém, como a entrada em um mercado de aluguéis depende da existência de renda das famílias e a obtenção das casas em conjuntos habitacionais é realizada por meio de sorteio, além de parte destas ainda estar por ser efetivada em Marabá, a eliminação do déficit 
habitacional não é algo que seja possível de vislumbrar em um horizonte de curto prazo. De tal maneira, as famílias de menor renda encontram nas ocupações urbanas a estratégia necessária para sua reprodução social, já que estas são as mais afetadas pelo déficit, pois 63,3\% do déficit de Marabá são relativos às famílias com rendimentos entre zero e três salários mínimos.

Como alternativa de (sobre) vivência na cidade, muitas destas famílias encontram nas ocupações urbanas a forma de se estabelecerem, de maneira que em 2010, segundo o IBGE (2010), existiam onze (11) Aglomerados Subnormais em Marabá, que abrigavam uma população de 28.823 habitantes. A afirmação destes aglomerados subnormais está relacionada com uma lógica de produção de espaço urbano, organizada a partir do estabelecimento de moradias em áreas de ocupação urbana e que tem no processo de instalação da ALPA um dos fatores de ampliação desta lógica. Nesse sentido, a Comissão Pastoral da Terra (CPT) é bastante esclarecedora a respeito desta relação:

A VALE e as autoridades governamentais, tem noticiado com frequência que, apenas, a instalação da siderúrgica vai gerar 17 mil empregos. O projeto ainda está em fase de estudos de impacto ambiental, mas, a propaganda da geração dos empregos já é feita há mais de um ano. Essa propaganda de interesses políticos tem promovido uma acelerada migração para a cidade de Marabá e região. A população pobre migra em busca de um emprego que não vai estar ao seu alcance devido não ter qualificação exigida. Com isso, vão inchando as periferias das cidades da região, submetidos a uma situação de violência, miséria e doenças constantes (CPT, 2010, p.1).

Faz-se necessário, também, discorrer a respeito dos conjuntos habitacionais que foram instalados em Marabá, através dos incentivos governamentais do PMCMV. Isso porque, juntamente com as ocupações urbanas, são nestes conjuntos que se estabelece a moradia efetiva, originando novos bairros na cidade, além de aumentar a demanda sobre os equipamentos e serviços públicos em uma determinada área da cidade. A partir de 2009 até 2015 foram criados três destes conjuntos em Marabá - Residencial Vale do Tocantins; Residencial Tiradentes e Residencial Jardim do Éden - que somam 3.468 novas residências. Todos estão localizados à margem direita do rio Tocantins, nos distritos urbanos de São Félix (Vale do Tocantins) e Morada Nova (Tiradentes e Jardim do Éden).

Porém, a construção das moradias poderia resolver, parcialmente, o problema do déficit habitacional marabaense. Entretanto, o que se percebe a partir da instalação destes conjuntos é a exacerbação de outros problemas, que contribuem para a ampliação das 
desigualdades socioespaciais em Marabá. Entre tais problemas está a falta de equipamentos públicos de saúde e educação nestes conjuntos, o que aumenta a demanda pelos equipamentos do entorno, problemas com abastecimento de água, entre outros (FIGURA 1).

Figura 1 - Reportagem de Jornal sobre a falta escolas e posto de saúde no Residencial Vale do Tocantins

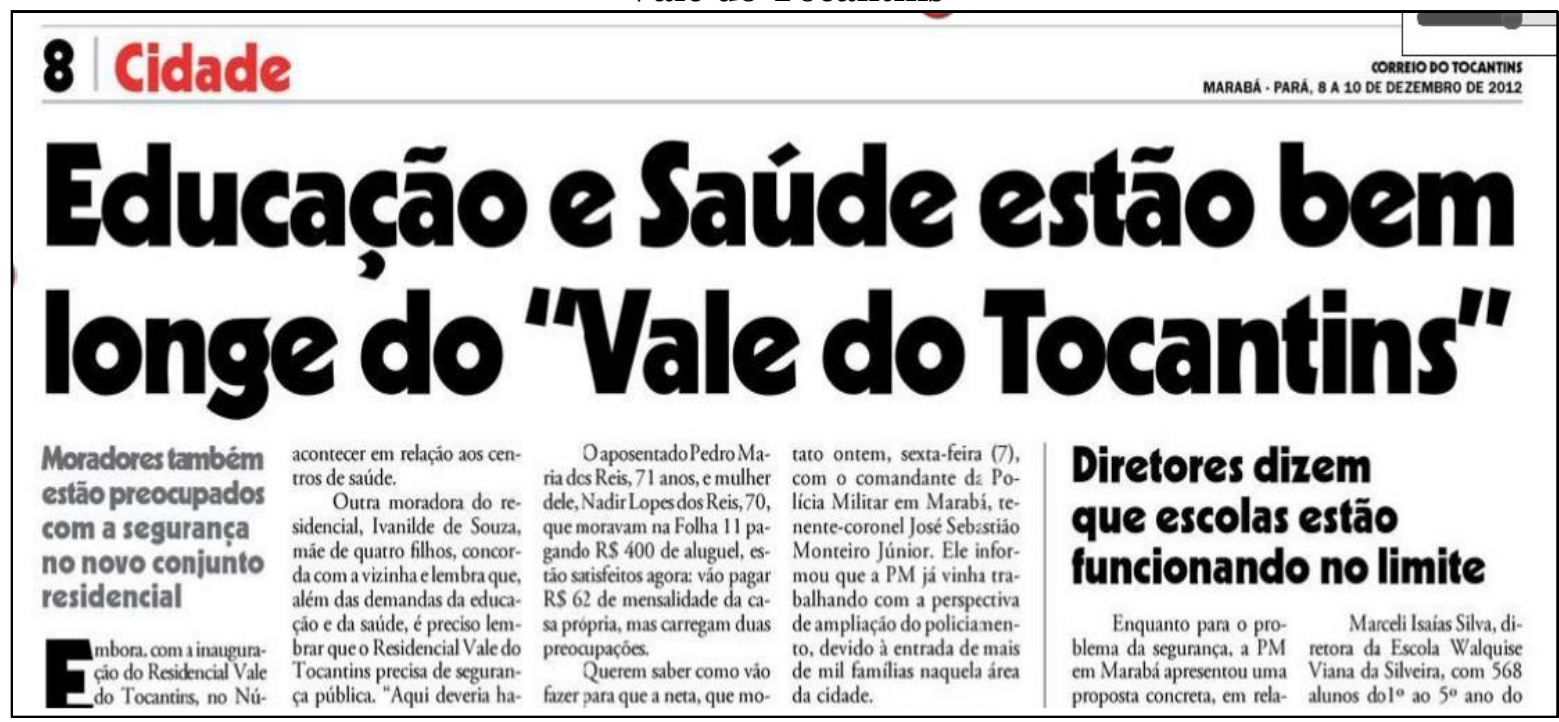

Fonte: EDUCAÇÃO (2012).

Por fim, a situação atual destes conjuntos habitacionais reforça o problema da inserção urbana (FERREIRA, 2012) destes, pois, apesar de estar próxima à BR-155, que lhes dá acesso, a articulação destes espaços com o restante da cidade, por meio dos deslocamentos de seus habitantes, é dificultada à medida que o transporte público coletivo não consegue atender a demanda criada com a instalação destes conjuntos. Atualmente, existe apenas uma linha de ônibus que adentra estes residenciais, o que torna premente o uso de soluções individuais de locomoção.

Como afirma Ferreira (2012, p.67) "a má localização de um conjunto habitacional eleva o tempo de deslocamento diário das famílias, promove piores condições de acessibilidade, e ainda reforça o modelo urbano baseado no automóvel". Isso se agrava à medida que a população é obrigada a se deslocar do bairro à procura de determinados equipamentos e serviços, inexistentes neste local. Por exemplo, nos núcleos de São Félix e Morada Nova, onde se localizam os conjuntos, não existem agências bancárias e hospitais, tornando necessária a busca por estes serviços "no outro lado da ponte". Nesse sentido, os 
conjuntos habitacionais em Marabá não têm garantido à sua população o direito à moradia digna, contribuindo, então, para o agravamento das desigualdades socioespaciais nesta cidade.

\section{Residencial Vale Do Tocantins: dificuldades de inserção urbana e desigualdades socioespaciais a partir da lógica estatal}

A partir de 2008, mas sobretudo após 2009, com a alteração do perímetro urbano, começam a serem lançados em Marabá os conjuntos habitacionais do PMCMV. A alterção do perímetro urbano foi importante neste momento pois, em sua totalidade, estes conjuntos estão localizados nos núcleos urbanos de São Félix e Morada Nova, que não faziam parte da área urbana antes de 2009. Assim, neste período surgiram os Residenciais Vale do Tocantins (2012), com 1.090 residências, no núcleo São Félix; Tiradentes (2013), com 1.410 moradias; Residencial Jardim do Éden (2015), ambos em Morada Nova; além do Residencial Magalhães, que está em fase de construção, o que totalizará 5.993 novas habitações disponíveis em Marabá a partir dos conjuntos habitacionais que, apesar da sua importância, não serão suficientes para equalizar o problema do déficit habitacional.

O Residencial Vale do Tocantins está localizado no núcleo São Félix1 (Mapa 2), nas proximidades do bairro São Félix Pioneiro, distante aproximadamente 650 metros da rodovia BR-155, que é a única via de ligação dos núcleos São Félix e Morada Nova com os demais núcleos urbanos de Marabá (Nova Marabá, Cidade Nova e Marabá Pioneira), visto que os primeiros estão localizados na margem direita do Rio Tocantins, cuja única forma de transposição é a ponte rodoferroviária, que possui apenas uma faixa de rolamento em cada sentido de tráfego, o que por vezes dificulta o acesso a estes núcleos da cidade. Após a construção e a realização dos procedimentos junto à CEF para a distribuição das casas aos moradores selecionados, estes receberam as chaves e puderam começar a ocupar o residencial a partir de dezembro de 2012. Isso explica o porque da grande maioria dos moradores estar vivendo no local há mais de 18 meses, ou seja, desde a entrega do loteamento, conforme pesquisa de campo.

1 O núcleo São Félix compreende os bairros São Félix Pioneiro, São Félix I, São Félix II, São Félix III, Jardim São Félix, Loteamento Vale do Tocantins, Loteamento Novo Progresso e o próprio Residencial Vale do Tocantins. Também abrigará o Residencial Magalhães (em construção). 


\section{Mapa 2 - Marabá (PA): Localização do Residencial Vale do Tocantins}

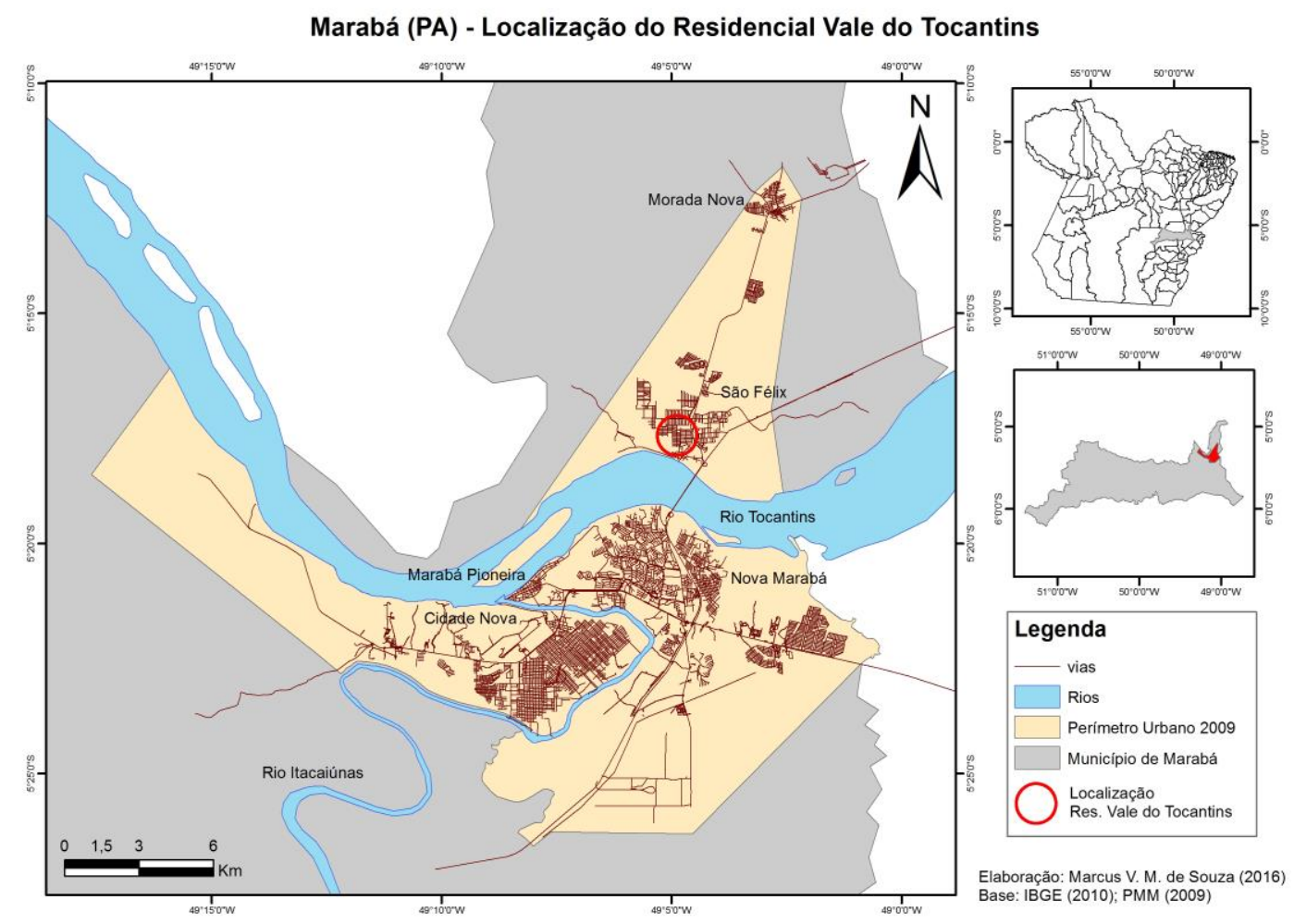

Elaboração: SOUZA, M.V.M. (2016)

Com relação à moradia anterior, é possível perceber que esta é bastante diversificada, com pessoas originárias de todos os núcleos da cidade e, inclusive de outros municípios. O destaque fica por conta daqueles que, anteriormente, viviam nos núcleos Cidade Nova (89 respostas) e Nova Marabá (77), sendo que, com relação à Cidade Nova, há de se ressaltar que destes 89 , um total de 54 são ex-moradores do bairro Liberdade. Além disso, outros dois aspectos precisam ser ressaltados.

Primeiramente, verifica-se que 39 famílias eram moradoras do núcleo São Félix, o que representa $13,6 \%$ do total. Isso significa que a maior parte dos moradores tiveram que se deslocar de outros núcleos da cidade para viverem no São Félix, já que a escolha de construir o residencial neste local não partiu deles e sim do poder público (e das alianças elaboradas para a transformação da área, até então rural, em urbana).

Um segundo aspecto que pode-se depreender é que, apesar da pequena quantidade, 30 famílias são originárias de Aglomerados Subnormais de Marabá, o que 
equivale a $10,5 \%$ do total do residencial. De tal forma é possível avaliar que os conjuntos habitacionais podem colaborar para a diminuição do déficit habitacional, por exemplo, das famílias de baixa renda ou conviventes, mas, para o caso dos aglomerados subnormais de Marabá, esta não tem sido a política mais efetiva de combate aos problemas com moradia, pelo menos no caso do Residencial Vale do Tocantins.

Apesar de resolver parcialmente o problema da moradia para esta população, isto não quer dizer que as condições de vivência no local são satisfatórias, sobretudo quando se analisa a presença de equipamentos públicos de consumo coletivo no residencial. Não foram entregues a esta população equipamentos como escolas e postos de saúde, o que obriga esta a ter de se deslocar para outras áreas da cidade, em busca de soluções para a sua reprodução social.

As conexões do Vale do Tocantins com as demais localidades da cidade se iniciam pela necessidade de busca pelo emprego. De acordo com os dados levantados, é possível avaliar que a Nova Marabá é o local da cidade que mais se destaca com relação ao emprego dos moradores do residencial, o que pode ser compreendido a partir da relativa proximidade com o bairro e também por ser esta uma das áreas mais importantes no que diz respeito à antiga moradia da população do residencial.

Como a maioria dos trabalhadores possui seu local de emprego fora do bairro (e mesmo fora do núcleo São Félix), torna-se preemente a necessidade de se deslocar do residencial para acessar o emprego. Nesse sentido, o veículo próprio aparece como a principal alternativa da população para o deslocamento casa-trabalho, respondendo por $45 \%$ destes, seguido do transporte público (29\%).

O transporte público, apesar de estar em segundo lugar, é uma alternativa importante (e necessária) para o deslocamento da população para realizar suas atividades cotidianas, como o trabalho. Entretanto, este é um serviço alvo de reclamações dos moradores durante da realização das pesquisas pois, segundo estes, existe um única linha que liga o bairro à outra margem do Rio Tocantins (Nova Marabá, Cidade Nova e Marabá Pioneira), com poucos horários durante o dia, o que faz com que alguns moradores se desloquem até a BR-155 para acessar outras linhas de ônibus, que passam com mais frequência pelo núcleo São Félix. 
Além do trabalho, o uso dos equipamentos públicos de consumo coletivo também gera a necessidade de deslocamento do residencial para outras localidades da cidade, em virtude da ausência de tais equipamentos no local. Por exemplo, nos núcleos de São Félix e Morada Nova não existem atualmente agências bancárias. De tal forma, toda a população destes núcleos, e não apenas do Residencial Vale do Tocantins, precisa se deslocar à outra margem do rio Tocantins quando necessário utilizar algum serviço bancário não realizado por seus correspondentes (Correio e Casa Lotérica).

Para o atendimento relativo à saúde a principal solução encontrada pela população do Vale do Tocantins são os Postos de Saúde do núcleo São Félix, sobretudo o posto de São Félix Pioneiro, cujas áreas mais próximas do residencial distam 400 metros deste equipamento e as mais distantes estão a pouco mais de um quilômetro; e também o posto do São Félix II, distante cerca de 1600 metros do residencial. Outros equipamentos também são buscados para o atendimento da saúde, como o Hospital Municipal de Marabá.

As dificuldades de transporte público no local faz com que a principal forma de acesso aos equipamentos de saúde seja a pé (48\%), principalmente para aqueles que fazem uso dos postos do núcleo São Félix. Isto poderia ser minimizado à medida que estes equipamentos estivessem presentes no próprio residencial.

A educação também é outro problema enfrentado pela população do residencial, já que de 2012 até o presente momento não existe nenhuma escola de educação básica instalada no bairro. No Vale do Tocantins, 39\% das residências possuem crianças que estão em idade para frequentar creches. Entre estas residências, em 55\% delas as crianças frequentam creches, enquanto que em $45 \%$ não, o que demonstra que há uma grande quantidade de crianças no bairro que necessitam deste equipamento e que não estão sendo atendidas.

Para o caso das escolas a situação é parecida, já que este equipamento também não foi entregue à população, juntamente com a moradia. Em $67 \%$ das residências do bairro existem crianças e/ou jovens em idade escolar, o que comprova a real necessidade da presença deste equipamento no local. Apesar de ser pequena, já é possível observar a evasão escolar no Vale do Tocantins, já que $98 \%$ das crianças/jovens em idade escolar frequentam este tipo de instituição. 
Assim como no caso da saúde, os equipamentos de educação do núcleo São Félix foram aqueles que tiveram que atender a demanda dos moradores do Residencial Vale do Tocantins, além daquela que estes já atendiam. Em 2012, quando da entrega do residencial, os diretores das escolas do São Félix se preocupavam com esta nova demanda, pois estes afirmavam que as escolas já estavam funcionando no seu limite (EDUCAÇÃO, 2012).

Diante da situação, uma das soluções encontradas para contornar este problema foi a criação do "turno intermediário", que fez com que os horários de aulas fossem diminuídos e as escolas passassem a funcionar, ao invés de três, em quatro turnos de aula (7$11 \mathrm{hs} ; 11-15 \mathrm{hs} ; 15-19 \mathrm{hs} ; 19-22: 30 \mathrm{hs}$ ), de forma a atender toda a demanda criada com a efetivação do novo residencial.

O lazer é outra atividade importante para a sociabilidade, que também foi analisado no residencial Vale do Tocantins. Nesse sentido, um dado chama bastante atenção, que é a quantidade de pessoas que alegaram não possuir atividade de lazer, não apenas pelo quantidade de respostas (111) mas também pelo volume que ela representa perante o total, que é de 39\%. Nenhuma outra atividade chega próximo a este item, sendo que os locais mais utilizados para os momentos de lazer, entre aqueles que afirmaram realizar este tipo de atividade, estão a casa de familiares, a própria casa e a Igreja.

A respeito dos aspectos relativos à percepção dos moradores sobre o bairro, foram levantados os dados sobre o que estes consideram como características positivas e negativas do residencial. Nesse sentido, há um fator que apresenta preponderância em relação aos outros: o fato de estar vivendo na casa própria, que foi apontado por 161 vezes pelos moradores como o principal aspecto positivo do local. Desta forma, percebe-se a importância dos conjuntos habitacionais, enquanto parte de uma política habitacional que beneficia, sobretudo, as famílias com menor poder aquisitivo. Em segundo lugar aparece a tranquilidade do bairro, apontada 63 vezes pelos moradores.

Com relação aos aspectos negativos é possível observar que a infraestrutura geral do bairro é o seu grande problema, já que foram apontados como aspectos negativos o estado de conservação das ruas (53 vezes); a infraestrutura de forma geral (54 vezes) e os problemas com a rede de esgoto - tubulação danificada - (40 vezes). Além disso, a provisão e ineficiência dos serviços e equipamentos públicos também desagrada a população do Vale do Tocantins, já que esta enumerou como problemas o transporte público (32 vezes), insegurança 
(46 vezes), a interrupção no abastecimento de água (23 vezes) e a ausência de escolas e postos de saúde (21 vezes) .

Por fim, junta-se a estes aspectos subjetivos aquele relacionado ao desejo de morar em outro local. A este respeito, o dado obtido foi surpreendente, já que 53\% dos moradores disseram ter sim o desejo de morar em outro local. Isto reforça que, apesar da casa própria, apontada com o principal fator positivo do bairro, isto não é suficiente para que a população viva de forma digna, já que para além da moradia, é preciso ter condições de deslocamento pela cidade e acesso aos equipamentos públicos de consumo coletivo, bem como o desejo de que este local apresentasse condições satisfatórias, com relação à sua infraestrutura. São tais aspectos que, ao longo dos anos posteriores à implantação do residencial, tem provocado movimentos contestatórios da população local, para a qual não basta apenas a moradia.

\footnotetext{
Em visita ao Correio do Tocantins, Marcos Sena, o presidente da Associação dos Moradores do Residencial Vale do Tocantins, localizado no Complexo São Félix, relata que desde a entrega das casas as problemáticas são constantes. Mazelas como esgoto a céu aberto, asfalto de má qualidade, transporte coletivo insuficiente, falta de posto de saúde e ruas alagadas em períodos chuvosos são as principais dificuldades enfrentadas pelos 5 mil moradores (POMPEU, 2014).
}

A partir do desejo expresso pela população de viver em outro local, esta foi questionada sobre o local de desejo de moradia. Nesse sentido, destaca-se a Cidade Nova, mencionada 51 vezes. Entretanto, ao desagregar este dado, pode-se inferir que destas menções referentes ao núcleo Cidade Nova, 22 delas são específicas do bairro Liberdade. Isto se explica pelo fato de que, como demonstrado no início da análise do residencial, 54 famílias tinham neste bairro a sua residência anterior e, portanto, uma considerável parte destas manifestou o desejo de retorno àquele bairro. Questionados do porque deste desejo de retorno ao Liberdade, os moradores alegaram que naquele bairro "tinha tudo", já que nele existem escolas, postos de saúde, comércio próximo, transporte, o que demonstra, mais uma vez, que apenas a moradia em si não é o único fator determinante para a reprodução social desta população. 


\section{CONSIDERAÇÕES FINAIS}

A lógica de estado na produção do espaço urbano marabaense, materializada na constituição de conjuntos habitacionais do PMCMV, tem, por um lado, colaborado para a diminuição do déficit habitacional, principalmente por possibilitar à população economicamente mais desfavorecida a oportunidade de deixar o aluguel e aceder à casa própria. Entretanto, como visto, isto não tem sido suficiente para ofertar a esta população uma melhor qualidade de vida e, ao contrário, tem contribuído para ampliar as desigualdades socioespaciais pelo espaço urbano desta cidade, à medida que a decisão de viver neste local não foi tomada pela população e sim pelas alianças entre o poder público e o capital imobiliário, já que a construção deste e de outros residenciais foi realizada em antigas propriedades, que foram compradas de um proprietário fundiário e, neste caso específico, até mesmo a mudança na legislação municipal foi necessária, com a ampliação do perímetro urbano.

Para o caso do residencial Vale do Tocantins há um agravante, que é a condição ambiental da área. Segundo Pompeu (2014), antes da construção destes conjuntos habitacionais, os terrenos haviam sido rejeitados por quatro empreiteiras, que se recusavam a construir na área, por ser este um terreno arenoso, que dificultaria no trabalho das fundações. De tal forma, percebe-se que prevaleceram os interesses de outros agentes sobre as reais necessidades da população que, desta forma, acaba por ser impossibilitada de apropriar-se de condições adequadas de (sobre)vivência no espaço urbano, condição esta fundamental para o estabelecimento de desigualdades socioespaciais.

Além de colaborar para a ampliação das desigualdades socioespaciais com o estabelecimento dos conjuntos habitacionais, a lógica estatal não conseguiu apresentar soluções eficientes para um outro aspecto, relativo ao déficit habitacional e às precárias condições de vida de parte da população de Marabá, que é o crescimento dos aglomerados subnormais e ocupações urbanas, onde a população incapaz de se fazer como parte da demanda solvável para o mercado imobiliário e também aquela que não foi agraciada com a casa própria nos conjuntos habitacionais, encontrará uma solução (temporária?) para sua sobrevivência na cidade de Marabá. 
A importância da produção espacial desencadeada pelo estado e pelos grupos sociais economicamente desfavorecidos, claramente influenciados pela valorização da terra urbana enquanto mercadoria denota o estabelecimento de desigualdades socioespaciais na produção do espaço urbano sem que, estes grupos sociais contribuam, decisivamente, enquanto causadores de tal processo. Isto aparece com maior evidência no caso dos conjuntos habitacionais, como o Residencial Vale do Tocantins, que instalou em uma área da cidade (núcleo São Félix) uma população composta por $82 \%$ de pessoas que, anteriormente, habitavam Marabá, porém, em outros núcleos urbanos (Cidade Nova, Nova Marabá e Marabá Pioneira).

Por um lado, a população, ao se candidatar a receber uma moradia em um programa habitacional, tem de se adequar às regras impostas. Entretanto, isso não significa que a decisão de escolher aquela área da cidade como local de moradia tenha partido desta, o que fica evidenciado no desejo, da maioria dos moradores do residencial aqui analisado, de viver em outro local. Induzir a população a se deslocar para outro local e não lhes oferecer condições mínimas para reprodução social na cidade, além de dificultar a inserção urbana do novo bairro, demonstra, claramente, a colaboração da lógica estatal para a consolidação das desigualdades socioespaciais.

Além do Residencial Vale do Tocantins, aqui analisado, existem atualmente outros dois conjuntos habitacionais do PMCMV já entregues em Marabá: o Residencial Tiradentes e o Residencial Jardim do Éden. Ambos estão localizados na mesmo região da cidade onde está o Vale do Tocantins, o que torna importante e necessária a realização de outras pesquisas, a fim de verificar se as condições de desigualdades socioespaciais apresentadas para a população do residencial aqui analisado se repetem nos demais espaços, a fim de entender, na totalidade da cidade, as causas e consequências da efetivação da lógica estatal da produção do espaço urbano.

\section{REFERÊNCIAS}

ABRAMO, P. O mercado informal e a produção da segregação espacial na América: a cidade COM-FUSA informal. In: LEAL. S.; LACERDA, N. (org.). Novos padrões de acumulação urbana na produção do habitat: olhares cruzados Brasil-França. Recife: Ed. Universitária UFPE, 2010. p.211-240. 
BOTELHO, Adriano. O urbano em fragmentos: a produção do espaço e da moradia pelas práticas do setor imobiliário. São Paulo: Annablume/FAPESP, 2007. 316p.

CARDOSO, Adauto Lúcio; ARAGÃO, Thêmis Amorim. A reestruturação do setor imobiliário e o Programa Minha Casa Minha Vida. In: MENDONÇA, J.P.; COSTA, H.S.M. (orgs). Estado e capital imobiliário: convergências atuais na produção do espaço urbano brasileiro. Belo Horizonte: Ed. C/Arte, 2011. p.81-104.

CARLOS, Ana Fani Alessandri. A prática espacial urbana como segregação e o "direito à cidade" como horizonte utópico. In: VASCONCELOS, P.A.; CORRÊA, R.L.; PINTAUDI, S. (orgs.). A cidade contemporânea: segregação espacial. São Paulo: Contexto, 2013. p.95-111.

A condição espacial. São Paulo: Contexto, 2011. 157p.

A (re)produção do espaço urbano. $1^{\mathrm{a} e d .} 1^{\mathrm{a}}$ reimpr. São Paulo: Edusp, 2008. 270p.

COMISSÃO PASTORAL DA TERRA (CPT). Diagnóstico das ocupações urbanas de Marabá. 2010. [s.n.t.].

EDUCAÇÃO e saúde estão bem longe do "Vale do Tocantins". Correio do Tocantins, Marabá, 8-10 dez.2012. Caderno Cidade, p.8.

FERREIRA, João Sette Whitaker (coord). Produzir casas ou construir cidades? Desafios para um novo Brasil Urbano: parâmetros de qualidade para a implementação de projetos habitacionais e urbanos. São Paulo: LABHAB/FUPAM, 2012. 200p.

FIX, Mariana. Financeirização e transformações recentes no circuito imobiliário no Brasil. 263f. 2011.Tese (Doutorado em Desenvolvimento Econômico), Instituto de Economia, Universidade Estadual de Campinas, Campinas, 2011.

FUNDAÇÃO JOÃO PINHEIRO (FJP). Déficit habitacional municipal no Brasil. Belo Horizonte: FJP/CEI, 2013. 78p.

GODOY, Paulo Roberto Teixeira. A produção do espaço: uma reaproximação conceitual da perspectiva lefebvriana. In: Revista GEOUSP, São Paulo, No 23, pp. 125-132, 2008.

IBGE. Censo Demográfico 2010: resultados gerais da amostra. Disponível em:

<http://www.ibge.gov.br/home/estatistica/populacao/censo2010/resultados_gerais_amostra/re sultados_gerais_amostra_tab_uf_microdados.shtm>. Acesso em 12 jan. 2014.

LEFEBVRE, Henri. The production of space. Oxford: Blackwell, 1991. 454p.

MARICATO, Ermínia. O "Minha Casa Minha Vida" é um avanço, mas segregação urbana fica intocada. In: Carta Maior [on line], São Paulo, 25 maio 2009. Disponível em: http:// http://cartamaior.com.br/?/Editoria/Politica/O-Minha-Casa-e-um-avanco-mas-segregacaourbana-fica-intocada/4/15160. Acesso em 28 out. 2015. 
MELAZZO, Everaldo Santos. Estratégias fundiárias e dinâmicas imobiliárias do capital financeirizado no Brasil. In: Mercator, Fortaleza, v.12, p.29-40, set.2013. Número especial (2).

POMPEU, Ulisses. Dilma será recebida por protestos de populares. Correio do Tocantins [on line], Marabá, 20 mar.2014. Disponível em:

http://www.ctonline.com.br/?inicial\&noticia=maraba\&titulo=Jv\%2FHmeb2KlOcYIcm. Acesso em 20 mar.2014.

RODRIGUES, Arlete Moysés. Desigualdades socioespaciais - a luta pelo direito à cidade. In: Cidades: Revista Científica, Presidente Prudente, v.4, n.6, p.73-88, 2007.

SHIMBO, Lúcia Z. O "segmento econômico" do mercado imobiliário e os programas públicos: faces da política habitacional contemporânea no Brasil. In: LEAL, S.; LACERDA, N. (orgs). Novos padrões de acumulação urbana na produção do habitat: olhares cruzados Brasil - França. Recife: Ed. UFPE, 2010, p.123-149.

SOJA, Edward. Geografias pós-modernas: a reafirmação do espaço na teoria social crítica. Rio de Janeiro: Zahar, 1993.

SOUZA, Marcus Vinicius Mariano. O projeto ALPA e a produção do espaço urbano em Marabá (PA): a cidade-mercadoria e as desigualdades socioespaciais. 297f. 2015. Tese (Doutorado em Geografia) - Universidade Federal de Uberlândia, Uberlândia, 2015.

SPOSITO, M.E.B. O chão em pedaços: urbanização, economia e cidades no Estado de São Paulo. 508p. 2004. Tese (Livre Docência) - Universidade Estadual Paulista, Faculdade de Ciências e Tecnologia, Presidente Prudente, 2004.

. Novos conteúdos nas periferias urbanas das cidades médias do Estado de São Paulo, Brasil. In: Investigaciones Geográficas, Boletín del Instituto de Geografia-UNAM, Cidade do México, n.54, p.114-139, 2004a.

. Loteamentos fechados em cidades médias paulistas - Brasil. In: SPOSITO, E.S.; SPOSITO, M.E.B.; SOBARZO, O. (org.). Cidades médias: produção do espaço urbano e regional. São Paulo: Expressão Popular, 2006. p.175-197.

\section{Autor}

Marcus Vinicius Mariano de Souza - Possui Graduação, Mestrado e Doutorado em Geografia, todos cursados na Universidade Federal de Uberlândia (UFU). Atualmente é professor na Universidade Federal do Sul e Sudeste do Pará (UNIFESSPA).

Artigo recebido em: 07 de julho de 2016 